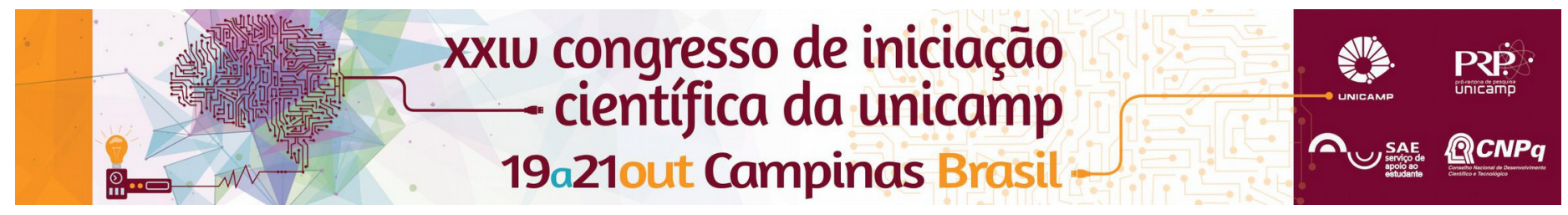

\title{
Processos de sedimentação e pedogênese das formações Santo Anastácio e Araçatuba (Bacia Bauru) na região de Presidente Prudente.
}

\author{
Thais Caroline Murer*, Alessandro Batezelli
}

\begin{abstract}
Resumo
A Bacia Bauru, objeto de estudo deste trabalho, é uma bacia do tipo intracratônica, formada pós-ruptura do continente gondwânico, a partir do evento de compensação isostática no Neocretáceo, após o acúmulo de $2.000 \mathrm{~m}$ de derrames de lavas basálticas que ocorreram no Cretáceo Inferior. Esta bacia guarda em sua história geológica eventos paleopedogenéticos que permitem caracterizar momentos de estabilidade tectônica, refinar as correlações estratigráficas e determinar paleoclimas. O projeto tem como objetivo caracterizar a transição entre os Grupos (Caiuá e Bauru) que formam esta Bacia, procurando relacionar os eventos de deposição e pedogenéticos que deram origem as formações Santo Anastácio (Grupo Caiuá) e Araçatuba (Grupo Bauru). O Geossolo Santo Anastácio está nesta transição e é interpretado como resultado da estabilidade no terreno no final do Cretáceo Inferior (parada na sedimentação). A Formação Araçatuba, assentada sobre os paleossolos, representa nova fase de sedimentação ocorrida no Cretáceo Superior após a reestruturação tectônica.
\end{abstract}

Palavras-chave:

Bacia Bauru, Paleossolo, Geossolo Santo Anastácio

\section{Introdução}

A Bacia Bauru, localizada no centro-sul da Plataforma Sul-Americana, apresenta em sua história geológica eventos paleopedogenéticos significativos que vêm sendo reconhecidos a partir da caracterização dos paleossolos. Embora o número de estudos sobre os paleossolos da Bacia Bauru encontrem-se em crescimento, eles não abordam aspectos estratigráficos, bem como sua importância para o entendimento da transição ente os Grupos Caiuá e Bauru.

Visando entender os processos tectônicos e climáticos ocorridos na transição do Grupo Caiuá e Grupo Bauru, foram estudados os paleossolos das formações Santo Anastácio e Araçatuba. Identificar uma superfície de descontinuidade entre as unidades Caiuá e Bauru, marcada por uma espessa e extensa camada de paleossolo (Geossolo Santo Anastácio, Fulfaro et al. 1999a e 1999b) sugere uma reestruturação tectônica no limite entre o Cretáceo Inferior e Superior. Para Fulfaro et al. (1999b) o depocentro sedimentar teve um deslocamento para norte.

A partir deste contexto, o principal objetivo deste estudo foi caracterizar a transição entre os Grupos Caiuá e Bauru, procurando relacionar os eventos de deposição e pedogênese que deram origem as formações Santo Anastácio (Grupo Caiuá) e Araçatuba (Grupo Bauru). Para isso a pesquisa foi de natureza bibliográfica, revisando autores que construíram o conhecimento a partir da identificação do paleossolo na Formação Santo Anastácio. $O$ trabalho também teve como objetivo a familiarização com os métodos de descrição de paleossolos.

\section{Resultados e Discussão}

Os estudos sobre a Bacia Bauru se iniciaram no começo do século 20 , e ao longo do tempo, diversos autores trabalharam de modo a organizar estratigraficamente a bacia. Fulfaro et al. (1999a) sugere que os arenitos maciços encontrados na Formação Santo Anastácio seriam fruto da alteração pedogenética no topo dos depósitos do Grupo Caiuá, após observar da base para o topo, um aumento de caráter maciço e a presença de orifícios nodulares, e propõem o termo Geossolo Santo Anastácio. Dessa forma o Geossolo representaria uma discordância temporal entre os grupos Caiuá e Bauru, sugerindo que a sequência depositada sobre a Formação Serra Geral teria sido formada em duas bacias distintas: Caiuá e Bauru

Batezelli (2015) e Silva (2014), endossam a ideia de Fulfaro et al. (1999a e b), constatando não só a superfície discordante entre os grupos Caiuá e Bauru, como aspectos paleoclimáticos (Silva, 2014).

\section{Conclusão}

Os estudos trouxeram confirmações sobre a proposta de Fulfaro et al. (1999). Destaque para importância do estudo dos paleossolos como ferramenta estratigráfica e evidência da reestruturação tectônica entre o Cretáceo Inferior e Superior na Bacia Bauru.

\section{Agradecimentos}

Agradecemos à FAPESP - Fundação de Amparo à Pesquisa do Estado de São Paulo - Projeto 2010/19787-2: Correlação Estratigráfica e Paleogeografia do Cretáceo Superior das Bacias Bauru, Sanfranciscana de dos Parecis.

Batezelli, A. Continental systems tracts of the Brazilian Cretaceous Bauru Basin and their relationship with the tectonic and climatic evolution of South America. Basin Research. 2015. doi: 10.111

Fulfaro, V. J.; Etchebehere, M. L. D. C.; Perinotto, J. A. J.; Saad, A. R. Santo Anastácio: Um Geossolo Cretácico na Bacia Caiuá. In: Simpósio Sobre o Cretáceo do Brasil, 5, Simposio sobre el Cretacico de América del Sur, 1, Serra Negra, Brasil. Boletim...Serra Negra, Unesp, P. 125-130. 1999a.

Fulfaro, V. J.; Etchebehere, M. L. D. C.; Perinotto, J. A. J.; Saad, A. R. Bacia Caiuá: Uma nova Bacia Cretácea na Bacia do Paraná. In: Simpósio Sobre o Cretáceo do Brasil, 5, Simposio sobre el Cretacico de América del Sur, 1, Serra Negra, Brasil. Boletim...Serra Negra, Unesp, P. 439-442. 1999b.

Silva, K. E. B. Caracterização Paleoambiental baseada nos Paleossolos da Formação Santo Anastácio - Bacia Bauru - SP. Campinas. Dissertação de Mestrado. Instituto de Geociências, Universidade Estadual de Campinas. 2014. 